\title{
Countermeasure Research on Blue Marine Economy Development of Dalian
}

\author{
Rong Liu, Liyan Chen \\ College of Economics and Management, Dalian University, Dalian, 116622, China \\ e-mail: liurong_dl@sina.com, chenliyan.love@163.com
}

\begin{abstract}
Keywords: Blue Marine Economy; strategy; harmonized development
\end{abstract}
\begin{abstract}
Blue marine economy is a series of economy industries relying on marine. It implements scientific development and utilization of marine resources, and brings out resource saving, environment friendly, development sustainable. Dalian is a large ocean city in China, with overwhelming superiority of Blue Marine Economy development. Recently the trend of Dalian ocean development was good, but there are also many problems. In this paper, the analyses are based on the status quo of Dalian Marine Economy and summaries of development experience. And we combine with the advantage and characteristic of Blue Marine Economic development in Dalian. Then corresponding to main mode and six main Dalian Marine Economy industries, we puts forward innovative and relevant countermeasures, which fits the development of Dalian economy and builds blue marine economic zone with characteristic of Dalian.
\end{abstract}

\section{Introduction}

Ocean bred our human beings, which contains rich resources to provide humans with water, food, energy, etc. To develop the Marine Economy nowadays, we cannot only take from the sea, but we should give top priority to protect marine ecology. In this way, we can give rise to implement scientific development and utilization of marine resources, and bring out resource saving, environment friendly, sustainable development, so as to achieve coordinated development of economy, society and ecology.

The future for global perspective development of Blue Marine Economy is looking good. Marine Oil Industry, Coastal tourism, Modern Marine Fisheries and Marine Transportation Industry have formed the four marine pillar industries in the world. The output of Marine Economy grows, promoting related industries development and increasing labor employment. The development state of Marine industrial structure is turning from the traditional Marine industries to Marine high-tech industry gradually rise together with traditional Marine industries transformation.

\section{The connotation of Blue Marine Economy}

Blue Economy is ocean economy in the new era, which embodies the concept innovation [1]. At present the definition of Blue Marine Economy has not been decided yet, though many scholars have stated the respective understanding of its connotation [2]. Their researches can be summarized as two views: one is narrow sense of Blue Economy, namely the Marine Economy; another is general sense, which bases on Marine economy as the main body and contains a variety of economic form integration.

In general, Blue Economy is a stereo industrial cluster, involving traditional industries, emerging industries and future high-tech industries [3]. It crosses region, trade and department, and needs multi-industry, multi-disciplinary, multi-field to work together to build emerging economies group. Blue Marine Economy refers to the development, utilization and protection of Marine Economy and it's the sum of all kinds of relevant social production activities. Its economic form is with Marine Economy as the main body, with sea and land overall development as the basis, with science and technology innovation as the leading, and with open, ecological, civilized and sustainable as the basic characteristics. Blue Marine Economy is a set of sustainable Marine Economic theory, with 
the development of Marine Economy as the main line, including Marine Fisheries, Coastal Tourism, Marine Transportation, Coastal Industrial, Marine Ecological Industry, etc.

Compared with the traditional Marine Economy, Blue Marine Economy pays more attention to sea and land overall arrangement, and makes coastal and hinterland economy complement respective advantages and rely on mutually, realizing comprehensive and competitiveness economic development.

Actually, to develop Blue Marine Economy is with system innovation as the support, and with the industrial economic development as the foundation. It effectively develops and utilizes more marine resources through the land resources, innovation platform of science and technology, industrial manufacturing, logistics transportation, investment system and other supports. It maximizes sea economic, social benefits and space scale, and realizes the sustainable development of Marine Economy.

\section{Status quo analysis of Dalian Marine Economy}

\subsection{Status quo of Dalian Marine Economy development}

Dalian Marine industry has entered the stage of comprehensive coordination since 2002, and made a solid pace in this new historical period. Recently, Dalian seized opportunities to expand innovation and increased the efficiency of comprehensive Marine management constantly, operating closely around the Marine and Fisheries related projects. Marine three industrial output ratios has achieved a historic change from "123" to "321".

In 2011, Marine economic output value is RMB 203.392 billion, and the added value is RMB 90.187 billion, which respectively increased $34.25 \%$ and $34.25 \%$. Dalian has approved 266 sea projects, 55,000 hectares of equaling area. The city has completed 53 sets of islands with no residents. Fishermen's annual per capita income reached RMB 18,300, increased RMB 2,000 more than last year.

\subsection{Good trend of Dalian Marine Economy development}

First, Marine Economy is increasing steadily and rapidly, and related industries always rank top in China. Dalian has already built a marine economic development new pattern preliminarily.

Secondly, marine industrial structure is optimizing ceaselessly. Social contribution of marine industries has improved obviously.

Thirdly, marine infrastructure is advancing rapidly, and infrastructure construction of coastal "one island and ten areas" is further improving.

Fourth, marine education is continuously enhanced. The key subject, provincial or above key laboratory, marine science parks and developing demonstration areas are increasing year by year.

Fifth, comprehensive marine management is further strengthened. Dalian Marine Functional Zone Plan and Port Plan have been established and implemented. The marine environmental protection engineering and sea area use system were put into practice further. Dalian has built marine disaster emergency systems in cities and counties two levels, enhancing maritime safety, rescue and relief works.

\subsection{The advantage and current models of Dalian Blue Marine Economy development}

Dalian has an important strategic position in economic and social development. This is a place where you can find broad seaside, meandering shoreline and dotted islands. Marine resources developing potential is tremendous. Dalian possesses the developing superiority of Blue Marine Economy, which contains marine resources, coastal location, marine development space and marine ecology, etc.

Current models are as follows: Marine Fishery industrialization promoting rapid development of Aquaculture Industry through marine ranching construction; Port Logistics cultivating new economic growth points; Coastal Tourism highlighting the marine ecological and cultural features; Shipbuilding Industry promoting industrial agglomeration; Sea Salt and Salt Chemical Industry making full use of marine mineral resources; Water Resource Utilization Industry giving priority to Desalination Industry. 


\section{Status quo and main problems of six main Marine Economy industries in Dalian}

\subsection{Marine Fisheries}

Dalian is an important fishery production base in North China. In 2011, fishery output value was RMB 64.6 billion, which possessed $31.76 \%$ of the Marine economy, and the added value was RMB 32 billion. The output of aquatic products was 1.26 million tons, of which advantage varieties possessed 65\%. The scale, grade and management level of processing industry rank top in China. Dalian has formed complete and diversity species of aquatic product processing series. The adjustment of Fisheries layout and structure is good, comprehensively promoting the "Ecological Fishery", "Healthy Farming" and "Clean Production" mode. Further maintained offshore fishery resources, controlled offshore fishing intensity, and continued to promote the development of pelagic fishery optimization.

Maritime space development and management mode is not scientific enough. Fisheries resources were relatively shrinking recently. Fishery space environment quality declined, while water pollution prevention and control work has not been fully appreciated. Few enterprises and fishermen participate in aquaculture proliferation activities, that should be the principal part. The quantity of pelagic fishery workers is not enough and the quality of existing personnel is not high. Both the intensive processing of aquatic products and new market development is insufficient. And aquatic product terminal market construction, cold chain and logistics system construction should be strengthened more.

\subsection{Marine Transportation}

Dalian port is the second largest container transship port in China. Port development direction is Yellow Sea and Bohai Sea both sides balanced development. Dalian Marine Transportation Industry output value reached RMB 5.372 billion in 2011. The coastal port cargo throughput was 340 million tons, which was in the seventh in China and eighth in the world. Container throughput has maintained high growth these years. There are 196 port berths and 86 international routes opened. It's an important sea lanes and the main traffic hub of Northeast Asia. Dalian has formed land, sea and air crisscrossed transportation network already.

Port logistics standardization level is still low, and the capability of public infrastructure set is not completed. Equipped port ability doesn't match with the hinterland economic structure. Port competition is more intensely because port hinterland overlaps outer ports. The difficulty of obtaining supplied goods has increased. Dalian still lacks high quality modern logistics talents.

\subsection{Coastal Tourism}

Dalian is an important coastal tourist city and the center in Northeast Asia. According to statistics, Dalian Coastal Tourism revenue increased to RMB 65.02 billion in 2011, of which the average annual growth was $20.1 \%$ for five years. The resources of coastal tourism are very rich here. And there is unique geological landscape with coastal areas such as natural and cultural landscape, marine animals and plants, unique hydrological landscape and precious marine products. Its city reputation is extremely high, deeply attracting numerous domestic and foreign customers.

Parts of the coastal scenic area are lack of sustainable development and marine ecological environment protection consciousness. Dalian coastal tourism product characteristic is not bright, lacking theme characteristic and cultural heritage tourism products. The development and utilization scale of tourism information resources is smaller than others.

\subsection{Shipbuilding Industry}

Since the tenth five-year, Dalian shipbuilding production capacity was from 1 million tons to 8 million tons, accounting for more than $10 \%$ of national market share. 2006-2011, Dalian shipbuilding gross value output increased from RMB 14.6 billion to 40.8 billion, and the annual growth rate was 22.8\%. Dalian Shipbuilding has a long history and excellent geographical conditions. There are labor resources advantages, attracting lots of talents from peripheral provinces and foreign counterparts. Both industrial base and ship supporting industry has advantages.

Ship supporting capacity lags behind the shipbuilding capacity. Marine core equipments still need to import. Many supporting enterprises positions as low level products and their technological content is relatively low. Shipping professionals cannot meet the development needs now. Due to 
the low industrial concentration, shipbuilding related enterprises are short of competitiveness. 4.5 Sea Salt and Salt Chemical Industry

Annual sea salt production capacity of Dalian is 700,000 tons, of which $80 \%$ is for Stalinization industrial production, and the rest for civil salt and export. Dalian has about 1,900 km long coastline and abundant water resources. Its ocean salinity is higher than common oceans, and tidal flats area is larger. Meteorological condition is suitable for sea salt production. Many skilled workers of rich experience are innovating on production process constantly. Convenient traffic condition brings low freight.

There is sea salt excess capacity and insufficient coastal resource use. The technological content is low, and the development and utilization of liquid salt is still in low level. Related enterprises have not been formed scale and industrialization, especially deep processing brine chemical industry products.

\subsection{Seawater Utilization Industry}

Dalian locates at the southern tip of Liaotung Peninsula, with coasts on three sides, so it has the natural advantages of seawater utilization. Current seawater utilization includes direct utilization, desalination, seawater chemical resources comprehensive utilization and energy utilization. Dalian is the only pilot city for the large-scale application of seawater source heat pump technology in China. Water quality of inshore area here is good, and the average temperature of seawater is low. It's convenient to get seawater to use in any season. Dalian has completed seawater desalination device design using membrane separation technology with capacity of 5,000 tons/day, and mastered multi-effect evaporation desalination core technology in ten thousand tons level.

Seawater use unit is in low industrialization degree and small scale. Lacking application and promotion of seawater desalination equipment, the quality of desalinated water is poor. Seawater utilization always belongs to enterprise spontaneous behavior.

\section{Countermeasures and solutions of Dalian Blue Marine Economy development}

\subsection{The government macro-control countermeasures}

Work out and implement comprehensive development strategy of Dalian Blue Marine Economy coordinating overall. Optimize industrial structure, and vigorously develop emerging and potential marine industries [4]. Improve Hi-tech content and the development vitality of marine economic science. Speed up system and mechanism innovation. Enhance marine investment soft environment and cultivate talents through various channels. Furthermore, raise civil marine ecological protection consciousness.

Promote industry-university-research cooperation and innovation. Government should establish research projects to priority, and construct public technical service platform oriented marine economy, integrating R\&D, technology consulting and technology services. Furthermore, organize industrialization talent union, and establish the reasonable and effective management system and operation mechanism. Give full play to promote independent innovation ability.

Set up blue marine economic development funds. Build foundation team to formulate association rules and establish reasonable and effective management system and operation mechanism. Government should encourage large or leading marine enterprises, social groups, personal donations and other fund sources. Funds key support marine enterprises to cultivate new varieties and develop new technology and products. Funds can set up a special website and attempt to implement compensable use. Fund operation and use should accept regular supervision and inspection of the relevant council.

Expand publicity of Blue Marine Economy development. Through holding various ceremonies, exhibitions, trainings, lectures and other science education activities, improve the civil awareness of marine ecology, marine resources and environment, and guide the masses to participate in the marine management related works. Especially, raise the related knowledge popularity of enterprises and fishermen which is the marine fishing subject, to let the blue marine economy development related knowledge into public life.

5.2 The micro industry countermeasures 


\subsubsection{Marine Fisheries}

Promote the high-end development of modern marine aquaculture, and consolidate traditional start position of Dalian aquaculture industry. Optimize maritime space development and management mode, and construct marine aquaculture with marine ranch industry, fishing industry, coastal tourism and port into industrial synthesis.

Persist in development strategy of ocean-going incremental efficiency, offshore reduction efficiency, and accelerate ocean pasture restoration. Protect existing marine fishery resources restorative growth and artificial breeding normal growth, and raise high seas fisheries development level, and continue to optimize pelagic fishery development. Set up a marine fishery breeding discharge cooperation mechanisms with related enterprises and fishermen as the principal part. Develop pelagic fishery practitioners, and formulate preferential policy to give more financial support.

Promote Marine Fisheries economic modernization. Actively develop competitive aquatic products into meticulous and deep processing. Expand domestic and foreign markets, and highlight aquatic products construction of market function, quality safety system, cold chain and logistics system, to implement brand strategy. Strengthen five major fishery aquatic products quality safety and supporting system construction, including original good species system, aquaculture disease prevention and control system, fishery information technology popularization system and market system.

\subsubsection{Marine Transportation}

Promote port function adjustment, and continue to optimize the port layout, so as to form industry trend of reasonable labor division, complementary advantages and coordinated development. Perfect system construction of key material transportation, land transportation, the port transportation and other supporting infrastructures, and focus on integrated transport network diversified construction with the port as its core. Cultivate comparative advantage and core competitiveness of Dalian port, and actively promote port linkage, forming win-win cooperation of horizontal ports integration. Open up more international routes and transshipment, and adjust the shipping capacity structure. Through multiple channels, introduce funds and personnel to participate in the port logistics industry.

\subsubsection{Coastal Tourism}

Improve the quality of coastal environment, and promote plans and assessments of coastal tourism ecological environment [2]. Strengthen publicity and education into every scenic spot, and strengthen regional cooperation and communication. According to tourists travel demand in different seasons and different customer market, carry out various projects, attracting the off-season tourists. Dig deeper into seaside tourism culture connotation of Dalian to popularize unique seaside tourism products system.

\subsubsection{Shipbuilding Industry}

Vigorously develop the ship supporting industry, and strengthen regional collaboration, so as to promote ship manufacturing industry agglomeration and form industrial clusters in Dalian. Accomplish the talent training base construction, and build high-quality scientific research team, attracting and agglomerating high-level shipping talents. Strengthen industry-university-research joint production and interaction, develop and construct hi-tech, high value-added and high-end product ships, so as to promote modern shipbuilding mode and guide the ship companies to increase investment in R\&D. Set up investment and financing platform, industry information platform and industry-university-institute cooperation platform. In science and technology innovation, tax, finance and other aspects, give more support and make preferential policies.

\subsubsection{Sea Salt and Salt Chemical Industry}

Adjust the layout to combine the sea salt production and seawater desalination and to complete production process. Take scientific and technological innovation as the core driving force and important way of sea salt industry development, and improve salt production technological content and competition level, so as to accelerate the development of varieties and series salt to serve different needs from different levels of consumer groups [5]. Improve the whole industry efficiency and the worker income, too. Promote salt making enterprises integrate reorganization, so as to 
achieve regional industrial upgrading. Focus on the construction of large saltworks and salinization enterprises, so as to improve the industrial concentration.

\subsubsection{Seawater Utilization Industry}

Fill the blank field of large-scale desalination in Dalian, to develop seawater chemical comprehensive utilization. Vigorously support seawater source heat pump technology development, and improve the scale and industrialization level of seawater utilization. Actively develop and promote related technologies, such as seawater direct use and desalination technology [4]. Develop industry leaders and industry-university-research combination. Form complete sets of equipment system integration capabilities as soon as possible, prompting seawater use industry into emerging industry of strategic importance in Dalian.

\section{Conclusions}

Dalian is a costal city and finds its development from the sea, so marine activities here have a long history. Dalian has formed a comprehensive system of marine economy development, but still has certain disparity when compared with other coastal cities. Facing new marine changes and challenges in the new period, Dalian should continually innovate and actively explore new path to implement strong ocean city. Increase investment, development and protection of marine relevant industries, and speed up the strategic marine undertaking development, in order to realize the rapid growth of Dalian GDP per capita and economic and social comprehensive, coordinated and sustainable development. Today and for the foreseeable future, Dalian becomes the leader city of the northeast old industrial base revitalization and national strategy development in Liaoning coastal economic belt. In this paper, the research also contributes to blue marine economics research.

\section{References}

[1] Researching Group of Development of Marine Economy of the World, "Research on Comparison of Marine Economy of Main Coastal Countries,” Statistical Research, pp. 43-47, September 2007.

[2] Y.F. Wu, "Marine Economy: Concept, Feature and Developing Path," Industrial Economic Review, pp. 125-131, May 2010.

[3] Q.B. Di, and X.J. Wang, "Research on Sustainable Development of Marine Economy in Dalian,” Resource Development \& Market, pp. 887-891, 2010.

[4] J.Y. Li, and B. Yin, "The Practical Demonstration about Harmonized Development Between Dalian City Economy and Liaotung Peninsula Ocean Economy,” Journal of China University of Geosciences(Social Sciences Edition), pp. 36-41, May 2005.

[5] Y. Wen, and G.J. Ni, "Enlightens from the Australia's development strategy on marine industry,” Chinese Fisheries Economics, pp. 79-82, 2008. 